\title{
Polish Society of Gynecologists and Obstetricians recommendation on the use of antiseptics for treatment of inflammatory vaginitis
}

\author{
Mariusz Zimmer ${ }^{1}$, Hubert Huras $^{2}{ }^{\circledR}$, Pawel Kaminski ${ }^{3}$, Agata Karowicz-Bilinska ${ }^{4}$, \\ Krzysztof Drews ${ }^{5}$, Tomasz Fuchs ${ }^{1}$, Michal Pomorski ${ }^{1}$ (]) \\ ${ }^{1} 2^{\text {nd }}$ Department of Gynecology and Obstetrics, Wroclaw Medical University, Wroclaw, Poland \\ 2 Jagiellonian Univeristy Collegium Medicum, Department of Obstertics and Perinatology, Cracow, Poland \\ ${ }^{3}$ Department of Gynecology and Oncological Gynecology, Military Institute of Medicine, Warsaw, Poland \\ ${ }^{4}$ Pathology of Pregnancy Department Medical University of Lodz, Poland \\ ${ }^{5}$ Department of Perinatology and Women's Diseases, Poznan University of Medical Sciences, Poland
}

\begin{abstract}
Undertook the analysis of literature, specialist knowledge and clinical experience on treatment options for non-specific vaginal inflammations of bacterial, fungal, mixed and unknown aetiology.
\end{abstract}

The recommendation presents the current state of knowledge on this subject on the day of the published analysis. However, the expert group reserves the right to update this position in the event of new and significant scientific reports.

\section{INTRODUCTION}

Research on the vaginal ecosystem dates back to the nineteenth century and is associated with Döderlein's description of the role and significance of lactobacilli. These gram-positive bacteria were then assigned the role of maintaining normal vaginal secretions. Further studies have shown that other aerobic and anaerobic bacteria are also present in the vagina and form the vaginal ecosystem. This physiological bacterial flora of the vagina creates a sophisticated and closed ecosystem. It can change depending on woman's age, her hormonal status, especially estrogen, sexual activity, performed vaginal procedures, drugs and exposure of vaginal mucosa to external substances [1].

Changes in the quantitative and qualitative ratio of the vaginal bacterial flora, in the absence of an infective factor, were previously called Non-specific Vaginitis (NSV) and are now referred to as Bacterial Vaginosis (BV).

Bacterial vaginosis (BV) means changes in vaginal bacterial flora. It consists of the reduction of lactobacillus producing hydrogen peroxide and an increase of other microorganisms. These include Gram-negative bacteria (Gardnerella Vulgaris, Prevotella sp., Atopobium vaginae, Porphiromonas spp., Mobiluncus spp., Bacteroides spp. and many other) that thrive in the anaerobic environment.

Expansion of Gardnerella colonies leads to the formation of a biofilm rich in proteolytic enzymes on the surface of epithelial cells, which causes exfoliation of the epithelium creating colonisation sites for other anaerobes [1, 2].

Vaginal ecosystem changes observed in BV also predispose to HSV-2, Trichomonas vaginalis, Neisseria gonorrhoeae and Chlamydia trachomatis superinfections. The risk of HIV infection and transmission increases. Also, chronic BV is conducive to the survival of HPV infection, and patients have a higher risk of being diagnosed with abnormal cells in a cytological examination, and thus, under certain favourable conditions, a higher risk of developing CIN. Untreated BV predisposes to more frequent infections of the upper floors of the genital organ like the endometrium and appendages, including fallopian tubes. In pregnant women, BV is a risk factor for spontaneous miscarriage or premature delivery [2].

Imbalance in the composition of the vaginal bacterial flora, decreased number of Lactobacillus species (Lactobacillus acidophilus L. jensenii, L. brevies, L. Plantarum L. crispatus, L. casei, L. fermentum, L. Gasperi) leads to a change in the vaginal $\mathrm{pH}$ and the possibility of various type of ailment, including pathological and symptomatic excessive vaginal discharge.

The dominant symptoms of BV are discharge, often with a different colour and smell, discomfort, burning, itching, mucosal oedema, and dyspareunia. The clinical picture of vaginal infections and biochemical changes depends on whether the infection results from aerobic, anaerobic bacteria or fungal origin. Vaginal flora abundant for Lactobcilus 
bacteria results in vaginal $\mathrm{pH}$ increase above 6 and an increase of pro-inflammatory cytokines.

Differences in the composition of various elements of the human microbiome can lead to functional disorders, which may include the genital organs. The microbiome has a protective function by competing for nutrients and points of adhesion. It can also change with age. The bacterial flora composition can vary depending on the stage of life and hormonal status. Vaginal microbiome disorders may occur under the influence of antibiotic therapy, during menopause, during pregnancy, due to increased exposure to microorganisms, the use of hormonal drugs, and immunosuppression.

Disorders of the vaginal bacterial flora that change the $\mathrm{pH}$ of secretions can present with little or no symptoms. In these situations, the measurement of vaginal $\mathrm{pH}$ is of diagnostic importance for early asymptomatic, non-specific vaginal inflammation. Abnormal pH should prompt the clinician to implement optimal early therapeutic management.

Based on the aetiology, non-specific vaginal infections can be bacterial and non-bacterial.

The most commonly diagnosed bacterial infections are BV - ( $20 \%$ to more than $60 \%$, depending on the source), followed by Candida-type infections (17\%-39\%) and infections caused by Trichomonas (4\%-30\%). Approximately every woman, at least once in her life, has a bacterial or fungal infection of the vagina $[1,2]$.

The second group of infections is fungal inflammation, with the most common form being candidiasis. Infections with other types of fungi occur less often. Candida infections are diagnosed based on the symptoms of vaginitis and vulva in the presence of the microorganisms mentioned above. In the case of fungal infections, Candida albicans accounts for $80 \%$ to $92 \%$ of vaginal and vulvar mycoses.

Diabetes, antibiotic therapy and immunosuppression are predisposing factors for the rapid growth of yeast colonies [1].

Factors that cause vaginal infection and subsequent symptomatic inflammation may also have a mixed aetiology: bacterial-fungal.

Bacteriological smears or cultures are not always available for diagnosis or require time to obtain a result. Therefore, the introduction of treatment before obtaining culture results is justified for antiseptic drugs. Effectiveness of these drugs is described in numerous reports $[3,4]$.

In postmenopausal women, due to a decrease in estrogen levels, atrophic genital lesions are common, which are the primary cause of developing non-specific vaginal inflammation.

Menopausal sex hormone deficiency causes an increase in vaginal $\mathrm{pH}$ and disappearance of physiological bacterial flora, which consequently increases the susceptibility to infections, mainly caused by bacteria migrating from the vulva and anal area (Streptococcus sp., Enterococcus sp., E. coli). Vaginal swabs have a higher incidence of severe leukocytic reactions and poor exfoliation of epithelial cells. The decrease in the physiological vaginal flora coexists with the appearance of numerous pathogens.

In postmenopausal women, Gram-positive cocci are 2.5 times more common than before menopause. Staphylococcus aureus strains are isolated in bacterial cultures ( 5 times more often than before menopause), Corynebacterium sp., (3 times more often), Streptococcus agalactiae and Enterococcus faecalis (2 times more often), E. coli (2 times more often), and also K. pneumoniae, P. mirabilis, C. freundii, not seen before menopause. Due to lack of glycogen and increased $\mathrm{pH}$ in the genital tract, strains of Candida albicans occur less frequently than in the group of premenopausal women [5].

Among the etiological factors of inflammatory vaginosis in women of childbearing age, bacterial aetiology remains the first, although a significant increase in the percentage of fungal infections has been observed in recent years. In turn, 1/3 of vaginitis in postmenopausal women has a bacterial, fungal or trichomoniasis aetiology. The remaining $2 / 3$ consist of vaginal atrophy, allergic factors, dermatological causes, and general diseases [5].

The standard of management in women with decreased estrogen levels is the elimination of inflammation. In the second stage by local estrogenization, the vaginal epithelium is restored. A similar effect is obtained by using laser vaginal revitalisation. This method seems to have particular application in women with contraindications for estrogen use $[6,7]$.

The current recommendations of the Center for Disease Control and Prevention (CDC) on the treatment of BV include treatment with antibiotics and chemotherapeutic agents (clindamycin, metronidazole, tinidazole) used orally or vaginally. These methods of treatment are associated with a reasonably good prognosis in terms of short-term treatment rates, and unfortunately, in the long run, they do not prevent recurrence of $B V$ in half of the cases.

The increasing resistance to antibiotics often used excessively in various forms of vaginitis, increasingly hinders the effectiveness of this therapy. Low efficacy of antibiotics has lead to limiting their use and replacing with antiseptics as the first-line treatment

It has been proven that the use of typical BV treatment with antibiotics and chemotherapeutic agents such as clindamycin and metronidazole, due to the increasingly occurring drug resistance, can be ineffective. In one study evaluating the effect of the above treatment on 30 bacterial strains grown in BV, it was shown that all strains tested were resistant to metronidazole and tinidazole, and $67 \%$ were also resistant to clindamycin [8]. 
The same is true for fungal infections. Due to the development of resistance to fluconazole by Candida, new therapeutic options are becoming necessary [9]. Also, new information on the structure and function of vaginal colonisation helps explain why antibiotic treatment has only limited use in infections involving microbial biofilms. The low effectiveness of antibiotics in preventing relapses is caused by the inability to eliminate bacteria associated with the vaginal biofilm, which is only temporarily suppressed, and quickly recovers its activity after stopping treatment. Besides, in the case of bacterial inflammatory vaginosis (BV), antibiotic treatment is often limited by the patient's general condition, and side effects associated with systemic administration may occur.

Therefore, in BV cases it is necessary to consider the forms of treatment known before the antibiotic era, but in a new technological edition using the achievements of modern pharmaceutical technologies, i.e. the use of vaginal antiseptics $[2,10]$.

Modern antiseptics are an alternative to antibiotic treatment, provided they combine a broad antimicrobial spectrum with low toxicity and high tissue biocompatibility. Topical antiseptics should now be the first choice in the treatment of local microbial vaginal infections.

Therefore, new antimicrobial agents that will act in a targeted manner without drug resistance and elimination of biofilm should dominate BV treatment as a first-line approach.

A full arsenal of vaginal products is available. They are tested for efficacy and safety in the treatment of non-specific inflammation of the vagina: $\mathrm{BV}$, candidiasis or viral infections.

They include:

- Polyhexamethylene biguanide (poliheksanid, PHMB)

$[2,11-28]$

- Dequaline chloride $[2,5,19,20,25,29,31,32]$,

- Povidone iodine [33, 34],

- Sliver ions [26, 30, 35-40],

- Boric acid [41-45],

- Chlorhexidine [46-48],

- Lactic acid bacteria with or without estriol $[49,50]$.

\section{BRIEF DESCRIPTION OF AVAILABLE ANTISEPTIC COMPOUNDS USED IN THE TREATMENT OF INFLAMMATORY VAGINOSIS OF VARIOUS ETIOLOGIES \\ Polyhexamethylene biguanide (poliheksanid, PHMB)}

Polyhexanide is an antiseptic with a broad spectrum of antimicrobial activity, including Gram-positive and Gram-negative bacteria, including MRSA, VRE, Escherichia coli, Pseudomonas aeruginosa, HPV, HSV-1, HIV viruses fungi (Candida albicans and others), protozoa causing keratitis (Acanthamoeba) [2, 11-13].
PHMB has three mechanisms of action:

- blocks adhesion of microorganisms to surfaces $[11,14,15]$,

- increases the liquidity and permeability of the bacterial cell membrane, which leads to a loss of its integrity and ultimately to cell death [11, 16-19],

- inhibits the metabolism of bacterial cells, has a higher efficiency in an environment with pathologically elevated $\mathrm{pH}$, and effectively prevents the re-emergence of biofilm [11, 19-22].

PHMB does not generate bacterial resistance and reduces the number of bacteria.

PHMB has Lactobacillus spp. sparring effects due to differences in cell- wall binding [23].

Polyhexanide (PHMB) has good efficacy and safety in the topical application in the treatment of non-specific vaginal infections of bacterial, fungal, viral and mixed aetiology as well as perioperative prophylaxis before vaginal procedures [24]. No adverse effects were found even with prolonged use, and the frequency of allergies is low $[25,26]$.

There are preliminary reports of the effectiveness of the treatment in doubtful cases and a small degree of cytological abnormalities in combination with an existing HPV infection. The above statements are very promising and may form the basis for further research in this direction [27].

\section{PHMB summary}

1. When used vaginally, PHMB has no inhibitory effects on Lactobacillus spp. growth [23].

2. The effectiveness of treatment without bacterial resistance and the elimination of biofilm [2,20].

3. Good tolerability with a small number of side effects even with prolonged use, low rate of allergic reactions $[25,26]$.

4. There is no convincing evidence of safety in pregnancy [28].

\section{Dequalinium chloride}

Dequalinium chloride as a quinoline derivative with a broad spectrum of biological activity, including antibacterial activity. It is used to treat vaginitis of bacterial, fungal, mixed and unknown aetiology [5].

It shows a broad spectrum of antibacterial activity against aerobic Gram-positive bacteria (Enterococcus faecalis Lactobacillus spp., Staphylococcus aureus, Streptococcus agalactiae, Streptococcus pyogenes), Gram-negative (Enterobacter spp., Escherichia coli, Klebsiella spp. Spp.), anaerobic bacteria (Bacteroides spp., Fusobacteria, Gardnerella vaginalis, Prevotella spp., Peptostreptococci, Poryphyromonas spp.) [19, 20, 29].

Clinical studies report its use in the treatment of vaginal inflammation in pregnant women (in all trimesters) and during lactation $[2,25]$.

This compound shows activity between 24 and 72 hours after the first dose.

Treatment usually lasts about six days. 


\section{Summary - dequaline chloride}

1. Efficacy in the treatment of BV.

2. Good tolerance - side effects occur at a frequency of $7.8 \%$ and may include mainly vaginal candidiasis, vaginal discharge, vulva and vaginal itching, and burning sensation within the vulva and vagina [29, 31, 32].

3. Due to the chemical nature of the substance - a quaternary ammonium compound, anionic substances such as soaps, detergents and surfactants, may additionally weaken the antibacterial effect of dequalinium chloride. Therefore, concomitant use of soaps, spermicides or irrigation is not recommended [29, 31, 32].

4. The manufacturer declares the possibility of use in pregnant women (in all trimesters) and during lactation [29].

5. It is contraindicated in cases of ulceration of the vaginal epithelium and vaginal part of the cervix, and in girls who have not yet started menstruation, i.e. have not reached $[29,31]$.

\section{Povidone-iodine}

lodopovidone (povidone-iodine) is characterised by a broad spectrum of action against Gram-positive bacteria, including strains of Lactobacillus spp., and Gram-negative bacteria, bacterial spores, viruses, protozoa, as well as fungi and yeast [33]

The main application according to Kramer's study is the use in disinfection of the surgical field, puncture sites, puncture, catheterisation, blood collection and as an active agent for short-term disinfectant use [34].

In the form of vaginal globules, it can be used in various types of vaginal inflammation, especially in bacterial vaginitis caused by Gardnerella vaginalis or infections by vaginal trichomes (Trichomonas vaginalis) [33]. It is used in the prevention of infections before surgical and diagnostic procedures within the vagina.

Due to the risk of thyroid dysfunction, povidone-iodine, in all forms of use, has additional restrictions, i.e.

- it should not be used for more than seven days,

- use before and after radioiodine treatment is contraindicated,

- combined use with octenidine and/or silver in the form of vaginal globules is contraindicated.

\section{Summary - povidone-iodine}

1. One-time preparation of the operating field - rinsing the vagina before the vaginal procedure.

2. Preparation of the vagina before vaginal surgery in the form of vaginal globules.

\section{Silver ions}

The antiseptic mechanism of silver ions is to inhibit cell division, damage the bacterial cell membrane, disruption transport in the cell, which leads to its death. Silver, as a local antiseptic, has a different mechanism of action from antibiotics and multidirectional effect on a bacterial cell, which means that the likelihood of developing resistance to silver is very low $[35,36]$.

The creation of TIAB silver, i.e. titanium dioxide particles on which active nanoparticles of $\mathrm{Ag}+$ silver ions have been deposited, in combination with benzalkonium chloride, has allowed an increase in antimicrobial and antiviral activity. The TIAB molecule is characterised by increased stability compared to other antiseptics based on silver compounds [30,37].

Silver in the TIAB molecule is effective against such microorganisms as: Staphylococcus aureus, Escherichia coli, Pseudomonas aeruginosa, Acinetobacterbaumannii, Klebsiellapneumoniae, Neisseria gonorrhoeae, Enterococcus faecalis, Listeria monocytosis, Streptomidisis, Gardneidcus) Chlamydia trachomatis. Besides, the spectrum of this form of silver also includes pathogens characterised by high antibiotic resistance, including staphylococci (MRSA) and vancomycin-resistant enterococci (VRE) and prevents the formation of bacterial biofilm.

Compounds containing the TIAB silver complex may also be recommended for patients with an abnormal low-grade cytological test or a low-grade ASC-US and L-SIL lesion. The mixture is useful in the treatment of inflammation and abnormal cytological smears $[26,38]$.

This compound is also characterised by high activity against yeast-like fungi: Candida albicans, Candida glabrata and mould - Aspergillus niger.

It has also been shown that it helps combat viral infection by showing antiviral activity, among others influenza (A / H1N1), polio, cytomegalovirus, smallpox, herpes zoster, HIV, HSV-1, HSV-2, hepatitis A, B, E, rubella, adenoviruses, herpes, mumps, enteroviruses, rhinoviruses, astroviruses or coronaviruses [37, 39, 40].

There are preliminary reports on the beneficial effects of silver compounds in the treatment of HPV infection. This requires further evaluation and validation of prospective studies involving a more significant number of people [26].

\section{Summary - silver ions}

1. Effectiveness in the treatment of bacterial infections, including those characterised by antibiotic resistance, including Staphylococcus (MRSA) and vancomycin-resistant enterococci (VRE).

2. A broad spectrum of anti-inflammatory properties including antifungal activity.

3. Possibility of use in II/III trimester of pregnancy.

4. Good tolerance and safety when applied locally.

\section{Boric acid}

Boric acid (Boric acid borax, orthoboric acid) - an inorganic chemical compound in the form of a weak acid 
(Acidum boricum). In nature, it can be found in some plants, in sea salts and minerals (e.g. in sassoline) [41].

The mechanism of bactericidal and fungistatic activity of boric acid is not fully understood. The bactericidal and fungistatic effect of boric acid is believed to be through penetration through the cell wall, and damage to the cell membrane of fungi [42].

The effectiveness of boric acid in the treatment of vaginal infections caused by Candida albicans has been proven [43] Boric acid products are also drugs of choice in the treatment of acute and recurrent fungal vaginitis and vulva caused by fungal species other than Candida albicans $[44,45]$.

Due to its unique drying, astringent and antiseptic properties, and low per cent solution, it is used as a disinfectant and to promote granulation in wound healing.

Boric acid in the form of vaginal globules is useful especially in the treatment of vaginitis caused by infection with C.glabrata and C.krusei.

\section{Summary - boric acid}

1. Maintenance therapy of especially fungal vaginosis and recurrent infections

2. Prophylaxis of $B V$ in patients with risk factors, especially during antibiotic therapy and hypoestrogenism.

\section{Chlorhexidine}

Chlorhexidine is a substance that has antibacterial activity. It damages the cell membrane of bacteria, which in turn leads to an increase in its permeability and cell breakdown.

Chlorhexidine has a strong bactericidal effect on Gram-positive bacteria, and less strongly on Gram-negative bacteria $[46,47]$.

Chlorhexidine resistance is observed for some pathogens such as methicillin-resistant $S$. aureus, as well as $P$. aeruginosa and $A$. Baumannie. In the treatment of bacterial vaginosis, chlorhexidine can be used vaginally.

Compared to standard therapies, topical treatment of bacterial vaginosis with chlorhexidine is characterszed by a low frequency of side effects [48].

\section{Summary - chlorhexadin}

1. Efficacy in the treatment of BV.

2. Element of prevention and supportive therapy before and after gyanecological surgical procedures.

\section{Lactic acid bacteria with or without estriol}

The administration of lactobacilli is intended to restore the physiological bacterial flora after topical or systemic treatment with anti-infectious agents or chemotherapeutic agents.

The combination of administration of the above lactobacilli with estriol increases the regenerative effect on the vagina, especially on its atrophic inflammation in the period of menopause and supportive therapy in menopausal hormone therapy (HTM).

The mechanism of action is based on strengthening the vaginal ecosystem after anti-infectious treatment by exogenous use of live lactic acid bacteria. There is no evidence of an adverse effect on the pregnancy or the condition of the fetus/newborn. Lactobacilli can be used in pregnancy, while a compound containing a combination of Lactobacillus acidophilus and estriol can be used during pregnancy with more significant benefit for the patient than the risk related to estrogen activity [49].

\section{Summary - lactic acid bacteria with or without estriol}

1. Used in the second stage of anti-inflammatory treatment as maintenance therapy.

2. To support that development of physiological vaginal flora in recurrent inflammation after treatment with other compounds, especially in the presence of vaginal atrophy [50].

3. Good tolerance.

\section{FINAL CONCLUSION}

The treatment of vaginal infections with non-antibiotic compounds is an effective method, especially in the case of BV, and can be successfully used as a first-line treatment instead of antibiotic therapy carrying possible complications and the risk of antibiotic resistance.

\section{REFERENCES}

1. Rekomendacje Polskiego Towarzystwa Ginekologicznego. Ginekol Pol 2014; 85: 557-559.

2. Bacterial Biofilms. Current Topics in Microbiology and Immunology 2008, doi: 10.1007/978-3-540-75418-3.

3. Weissenbacher ER, Donders G, Unzeitig V, et al. Fluomizin Study Group. A comparison of dequalinium chloride vaginal tablets (Fluomizin ${ }^{\circledR}$ ) and clindamycin vaginal cream in the treatment of bacterial vaginosis: a single-blind, randomized clinical trial of efficacy and safety. Gynecol Obstet Invest. 2012; 73(1): 8-15, doi: 10.1159/000332398, indexed in Pubmed: 22205034

4. Menard JP. Antibacterial treatment of bacterial vaginosis: current and emerging therapies. International Journal of Women's Health. 2011:295, doi: $10.2147 /$ ijwh.s23814.

5. Sobczuk A, et al. Stany zapalne pochwy u kobiet w wieku menopauzalnym. Przegląd Menopauzalny. 2007; 3: 155-161.

6. Pitsouni E, Grigoriadis T, Falagas M, et al. Laser therapy for the genitourinary syndrome of menopause. A systematic review and meta-analysis. Maturitas. 2017; 103: 78-88, doi: 10.1016/j.maturitas.2017.06.029.

7. Cruz VL, Steiner ML, Pompei LM, et al. Randomized, double-blind, placebo-controlled clinical trial for evaluating the efficacy of fractional $\mathrm{CO} 2$ laser compared with topical estriol in the treatment of vaginal atrophy in postmenopausal women. Menopause. 2018; 25(1): 21-28, doi: 10.1097/GME.0000000000000955, indexed in Pubmed: 28763401.

8. Alves P, Castro J, Sousa C, et al. Gardnerella vaginalis Outcompetes 29 Other Bacterial Species Isolated From Patients With Bacterial Vaginosis, Using in an In Vitro Biofilm Formation Model. The Journal of Infectious Diseases. 2014; 210(4): 593-596, doi: 10.1093/infdis/jiu131.

9. Marchaim D, Lemanek L, Bheemreddy S, et al. Fluconazole-resistant Candida albicans vulvovaginitis. Obstet Gynecol. 2012; 120(6): 1407-1414, doi: 10.1097/aog.0b013e31827307b2, indexed in Pubmed: 23168767. 
10. Verstraelen $\mathrm{H}$, Verhelst $\mathrm{R}$, Roelens $\mathrm{K}$, et al. Antiseptics and disinfectants for the treatment of bacterial vaginosis: A systematic review. BMC Infectious Diseases. 2012; 12(1), doi: 10.1186/1471-2334-12-148.

11. Koban I, Bender CP, Assadian O, et al. Clinical Use of the Antiseptic Polihexanide for Genital Tract Infections. Skin Pharmacology and Physiology. 2012; 25(6): 298-304, doi: 10.1159/000340063.

12. Polyhexanide. Meyler's Side Effects of Drugs. 2016: 859, doi: 10.1016/b978-0-444-53717-1.01315-9.

13. Allen $M$, White $G$, Morby $A$. The response of Escherichia coli to exposure to the biocide polyhexamethylene biguanide. Microbiology. 2006; 152(4): 989-1000, doi: 10.1099/mic.0.28643-0.

14. Hansmann $F$, Kramer $A$, Ohgke $H$, et al. Lavasept as an alternative to PVP-iodine as a preoperative antiseptic in ophthalmic surgery. Randomized, controlled, prospective double-blind trial. Ophthalmologe. 2005; 102(11): 1043-6, 1048, doi: 10.1007/s00347-004-1120-3, indexed in Pubmed: 16283191.

15. Rosin M, Welk A, Bernhardt O, et al. Effect of a polyhexamethylene biguanide mouthrinse on bacterial counts and plaque. Journal of Clinical Periodontology. 2001; 28(12): 1121-1126, doi: 10.1034/j.1600051x.2001.281206.x.

16. Ikeda $\mathrm{T}$, Ledwith $\mathrm{A}$, Bamford $\mathrm{CH}$, et al. Interaction of a polymeric biguanide biocide with phospholipid membranes. Biochimica et Biophysica Acta (BBA) - Biomembranes. 1984; 769(1): 57-66, doi: 10.1016/0005-2736(84)90009-9.

17. Gabriel G, Som A, Madkour A, et al. Infectious disease: Connecting innate immunity to biocidal polymers. Materials Science and Engineering: R: Reports. 2007; 57(1-6): 28-64, doi: 10.1016/j.mser.2007.03.002.

18. Gilbert P, Moore LE. Cationic antiseptics: diversity of action under a common epithet. J Appl Microbiol. 2005; 99(4): 703-715, doi: 10.1111/j.136 5-2672.2005.02664.x, indexed in Pubmed: 16162221.

19. Kaehn K. Polihexanide: A Safe and Highly Effective Biocide. Skin Pharmacology and Physiology. 2010; 23(1): 7-16, doi: 10.1159/000318237.

20. Hübner NO, Kramer A. Review on the Efficacy, Safety and Clinical Applications of Polihexanide, a Modern Wound Antiseptic. Skin Pharmacology and Physiology. 2010; 23(1): 17-27, doi: 10.1159/000318264.

21. Ikeda T, Tazuke S, Watanabe M. Interaction of biologically active molecules with phospholipid membranes. Biochimica et Biophysica Acta (BBA) - Biomembranes. 1983; 735(3): 380-386, doi: 10.1016/00052736(83)90152-9.

22. Ikeda T, Tazuke S, Bamford C, et al. Spectroscopic Studies on the Interaction of Polymeric In-chain Biguanide Biocide with Phospholipid Membranes as Probed by 8-Anilinonaphthalene-I-sulfonate. Bulletin of the Chemical Society of Japan. 1985; 58(2): 705-709, doi: 10.1246/bcsj.58.705.

23. Pelletier C, Bouley C, Cayuela C, et al. Cell surface characteristics of Lactobacillus casei subsp. casei, Lactobacillus paracasei subsp. paracasei, and Lactobacillus rhamnosus strains. Appl Environ Microbiol. 1997; 63(5): 1725-1731, indexed in Pubmed: 9143109.

24. Summary of medical product characteristics Infectvagin.

25. Kramer A, Roth B, Müller G, et al. Influence of the Antiseptic Agents Polyhexanide and Octenidine on FL Cells and on Healing of Experimental Superficial Aseptic Wounds in Piglets. Skin Pharmacology and Physiology. 2004; 17(3): 141-146, doi: 10.1159/000077241.

26. Scambia G. Role of TIAGIN ${ }^{\circledR}$ vaginal formulation in cervical reepithelialszation and high-risk HPV clearance in patients with low-grade cervical lesions. Italian Journal of Gynaecology \& Obstetrics. 2017; 1.

27. Gentile A, et al. A new non-invasive approach based on polyhexamethylene biguanide increases the regression rate of HPV infection. BMC Clinical Pathology. 2012; 12(17).

28. Kramer A, et al. Re-evaluation of polihexanide use in wound antisepsis in order to clarify ambiguities of two animal studies. Journal Of Wound Care. 2019; 28(4).
29. Rai M, Yadav A, Gade A. Silver nanoparticles as a new generation of antimicrobials. Biotechnol Adv. 2009; 27(1): 76-83, doi: 10.1016/j.biotechadv.2008.09.002, indexed in Pubmed: 18854209.

30. Summary of medical product characteristics Fluomizin

31. Petersen EE, Weissenbacher ER, Hengst $P$, et al. Local treatment of vaginal infections of varying etiology with dequalinium chloride or povidone iodine. A randomised, double-blind, active-controlled, multicentric clinical study. Arzneimittelforschung. 2002; 52(9): 706-715, doi: 10.1055/s0031-1299955, indexed in Pubmed: 12404887.

32. Mendling $\mathrm{W}$, et al. Use of locally delivered dequalinium chloride in the treatment of vaginal infections: a review. Arch Gynecol Obstet. 2016; 293: 469-484.

33. Summary of medical product characteristics Betadine.

34. Kramer A, et al. Konsensus w sprawie antyseptyki ran: Aktualizacja 2018. Consensus Guidelines, Skin Pharmacol Physiol. 2018; 31: 28-58.

35. Ricci C. Role of TIAGIN vaginal formulation in cervical reepithelialszation and high-risk HPV clearance in patients with low-grade cervical lesions. Italian Journal of Gynaecology \& Obstetrics . 2017; 29(1).

36. Rodriguez-Arguello J, Lienhard K, Patel P, et al. A Scoping Review of the Use of Silver-impregnated Dressings for the Treatment of Chronic Wounds. Ostomy Wound Manage. 2018; 64(3): 14-31, indexed in Pubmed: 29584609.

37. Mączyńska B, Junka A. Etiologia i patogeneza zakażeń pochwy u kobiet - srebro w cząsteczce TIAB jako alternatywna metoda leczenia infekcji. Okiem mikrobiologa. Forum Zakażeń. 2016; 7(3): 167-174, doi: $10.15374 / f z 2016027$.

38. Homola W, et al. Rozwój metod screeningu, diagnostyki oraz postępowania z nieprawidłowym rozmazem cytologicznym. GinPolMedProject . 2019; 53(3): 33-38.

39. Krakowiak W., Innowacyjna molekuła srebra TIAB w leczeniu zakażeń trudno gojących się ran. Biotechnologia.pl.

40. Dębski R, Drews K, Paszkowski T, et al. Stanowisko Ekspertów na temat zastosowania wyrobu medycznego Hexatiab ${ }^{\circledR}$ Softgel w przypadkach infekcji pochwy. Ginekologia i Położnictwo. ; 2018(2): 12-15.

41. Marquardt $C$, et al. Evaluation of the tissue toxicity of antiseptics by the hen's egg test on the chorioallantoic membrane (hetcam). Eur J Med Res. 2010; 15: 204-209.

42. Prutting SM, Cerveny JD. Boric acid vaginal suppositories: a brief review. Infect Dis Obstet Gynecol. 1998; 6(4): 191-194, doi: 10.1002/(SICI)109 8-0997(1998)6:4<191::AID-IDOG10>3.0.CO;2-6, indexed in Pubmed: 9812253.

43. Sebastian F. Infectious Diseases in Obstetrics and Gynecology. 2008, doi: 10.3109/9781439801994.

44. lavazzo C, Gkegkes ID, Zarkada IM, et al. Boric acid for recurrent vulvovaginal candidiasis: the clinical evidence. J Womens Health (Larchmt). 2011;20(8): 1245-1255, doi: 10.1089/jwh.2010.2708, indexed in Pubmed: 21774671.

45. Summary of medical product characteristics Albivag.

46. Mondello F, De Bernardis F, Girolamo A, et al. In vivo activity of terpinen-4-ol, the main bioactive component of Melaleuca alternifolia Cheel (tea tree) oil against azole-susceptible and -resistant human pathogenic Candida species. BMC Infect Dis. 2006; 6: 158, doi: 10.1186/1471-23346-158, indexed in Pubmed: 17083732

47. Summary of medical product characteristics Chlorivag

48. Di Vi, Mattarelli P, Modesto M, et al. In Vitro Activity of Tea Tree Oil Vaginal Suppositories against Candida spp. and Probiotic Vaginal Microbiota. Phytother Res . 2015; 29(10): 1628-1633.

49. Müller G, Kramer A. Biocompatibility index of antiseptic agents by parallel assessment of antimicrobial activity and cellular cytotoxicity. J Antimicrob Chemother. 2008; 61(6): 1281-1287, doi: 10.1093/jac/dkn125, indexed in Pubmed: 18364400.

50. Summary of medical product characteristics Gynoflor. 